\title{
Evaluation of the Surface of Nitinol after MR Polishing Process
}

\author{
Byung-Chan Kim1', Jung-Won Lee', Seok-Jae Ha1, Yong-Kyu Cho1, Dong-Sung Kang2, \\ Myeong-Woo Cho' \\ ${ }^{1}$ Department of Mechanical Engineering, Inha University, Incheon, Republic of Korea \\ ${ }^{2}$ WISYS, Gunpo-si, Republic of Korea \\ Email: chomwnet@inha.net
}

Received 17 December 2014

\begin{abstract}
Nitinol is used in various industries, especially for biomaterials. Generally, the surface integrity of sub-micron level and non-surface flaw is required in nitinol for biomaterial. However, surface flaws, such as scratches, pits, and residual stress, can occur on the polished surface, and it is difficult to remove these surface flaws. The corrosion is accelerated continuously and causes bad influence in the body. Therefore, in this study, conventional polishing and MR polishing were used to minimize the corrosion and residual stress when the nitinol is used as biomaterial. $X$-ray diffraction and Tafel extrapolation were used to investigate the residual stress and the corrosion, and the strain hardening was investigated by nanoindentation. Surface integrities were also evaluated by SEM image and surface roughness results. As a result, the increased residual stress in conventional polishing was decreased by MR polishing. The result of corrosion test was improved from $-301 \mathrm{mV}$ to $-\mathbf{2 8 0} \mathrm{mV}$. The residual stress was improved from $-\mathbf{3 8 . 1 8} \mathrm{MPa}$ to $\mathbf{- 3 1 . 1 7} \mathrm{MPa}$. Finally, it is certified that MR polishing can be used to minimize surface flaws and to improve the corrosion properties.
\end{abstract}

\section{Keywords}

Nitinol, MR Polishing, Corrosion Test, Residual Stress, Strain Hardening

\section{Introduction}

Nitinol which is well known as typical shape memory alloy is used artificial organ, such as stent, bone plate, condyle and hip joint, because of good biocompatibility. Nitinol should have a high accuracy and a precision surface integrity. However, because of the generated surface flaw for producing, such as scratch, pit, work-hardening and residual stress, the post-process should be needed [1]. This surface flaw can be minimized by general polishing method. In the polishing process of nitinol, due to heat and stress, the phase can be transformed. As a result, it is difficult to obtain the high precision surface. In particular, the residual stress causes work-hardening. In the surface with work-hardening, effective removal of deformed layer and surface flaw cannot be achieved due to different hardness by polishing process. After that, they promote stress corrosion crack. Implanted nitinol in body is easily exposed to corrosion environment by blood and saliva with chlorine or amino acid. Corrosion 
of nitinol for biomaterial can affect a primary cause of fracture in body [2] [3]. Therefore, the research for the post process should be essential to minimize the surface flaw.

Conventional polishing process is able to cause work-hardening, residual stress and subsurface deformed layer by delamination mechanism, and to decrease the corrosion properties. In this study, conventional polishing process was used to identify the surface flaw. MR (magnetorheological) polishing process, then, was used to minimize the residual stress and work-hardening, and to improve the surface roughness and the corrosion resistance. Surface roughness and SEM image were measured to evaluate the surface roughness after processes. Nanoindentation was applied to measure the hardness. X-ray diffraction method (XRD) was applied to measure the residual stress, and the corrosion characteristics were investigated by Tafel extrapolation.

\section{Polishing Processes for Analysis of Surface Defects}

\subsection{Conventional Polishing Process}

In conventional polishing, material removal is carried out by plastic deformation and friction due to relative motion between workpiece and polishing pad. Mirror and flattening surface can be obtained. The polishing system consists of sandpaper, polishing head (fixation and uniform pressure), holder, rotating plate and abrasive. To minimize the deformed layer, the pressure between polishing pad and workpiece is increased, occasionally. To obtain high polishing effect, the repetitive motion in radial direction is acquired (Figure 1). Figure 2 is a system that is used to experiment conventional polishing (MECAPOL P320). Rotational speed (100 rpm), polishing time (5 min), and pressure $(1.0 \mathrm{~N})$ were fixed, constantly.

\subsection{MR Polishing Process}

In MR polishing process, the form accuracy obtained by conventional polishing can be retained and the surface roughness can be improved. Also, MR polishing process can control the shear force through the viscosity changes with magnetic field. Figure 3 shows the principle of MR polishing process and experimental system. A magnetic field is applied to the rotating wheel, then, the rotating wheel is magnetized. MR fluid is supplied on the wheel surface and is stiffened by the applied magnetic field. Stiffened MR fluid layer acts as a polishing pad. The polishing area is formed when MR fluid is supplied into the gap size between workpiece and wheel. The abrasives can be reused by circulation system and is supplied onto the rotating MR fluid layer. To fix height of

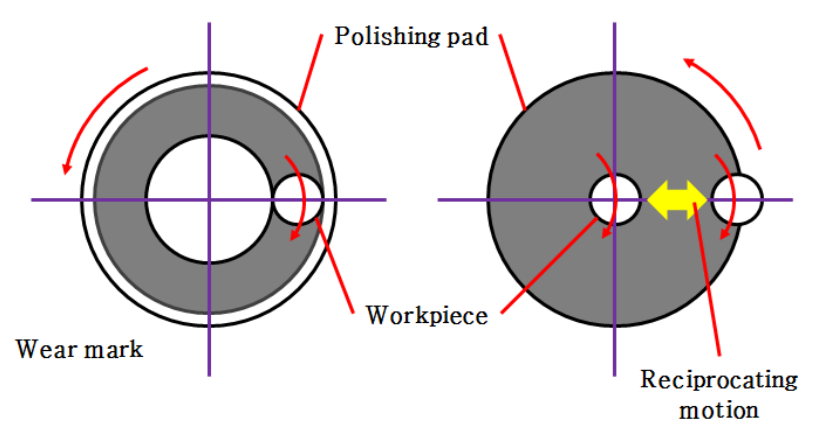

Figure 1. Principle of conventional polishing.

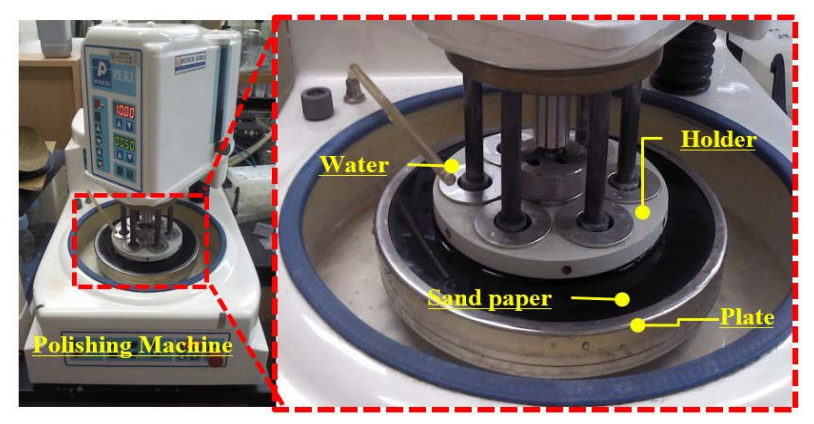

Figure 2. Experimental setup for conventional polishing. 


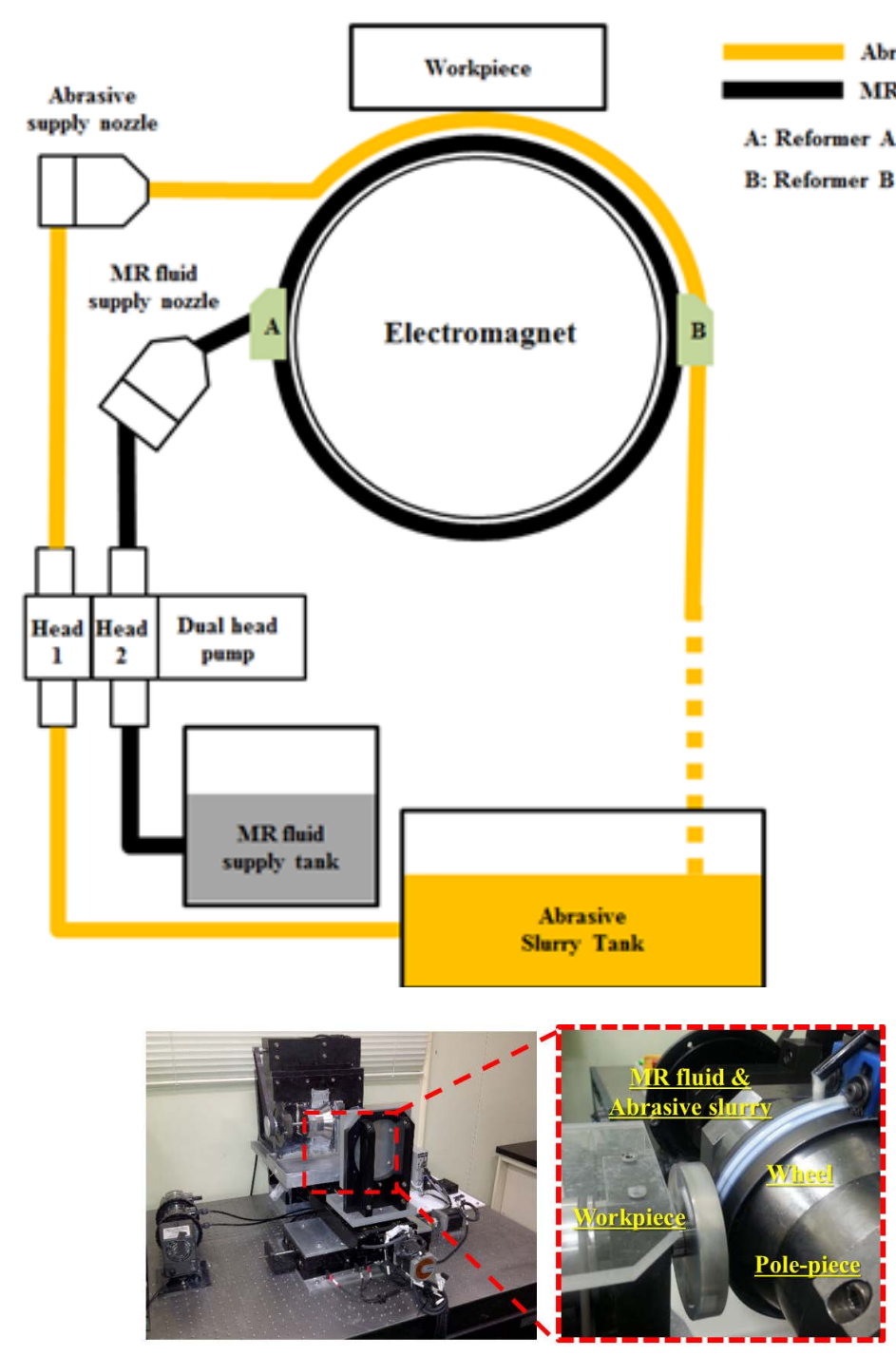

Figure 3. Experimental setup for MR polishing.

MR fluid for obtaining the uniform polishing results, the reformer was applied. In this study, the experimental conditions which can be obtained very fine surface roughness in previous study were selected. The investigation of surface roughness, residual stress, and corrosion characteristics were carried out in experiments. Experimental conditions were listed in Table 1 and Table 2.

\section{Results and Discussions}

\subsection{Analysis of Surface Roughness}

Figure 4 and Figure 5 show the measured 3D profile and the SEM image for the surface roughness after each process. As a result, surface roughness as $\mathrm{Ra}=12.91 \mathrm{~nm}, \mathrm{R}_{\max }=94 \mathrm{~nm}$ can be obtained. However, although $\mathrm{SiC}$ particle is small, surface flaw was still existed in SEM image because of the scratch and pit. It can be seen that conventional polishing process can cause increase the surface flaws.

On the other hand, very fine surface roughness $\left(\mathrm{Ra}=3.72 \mathrm{~nm}, \mathrm{R}_{\max }=50 \mathrm{~nm}\right)$ can be obtained from MR polishing process. Magnetized MR fluid which has a viscoelasticity performs function as a soft polishing pad. Nano sized abrasives is supplied onto the wheel surface for polishing the workpiece. The pressure and the normal force between particle and workpiece are smaller than that of conventional polishing, relatively. As a result of this, surface flaws cannot exist by MR polishing process [4]. 


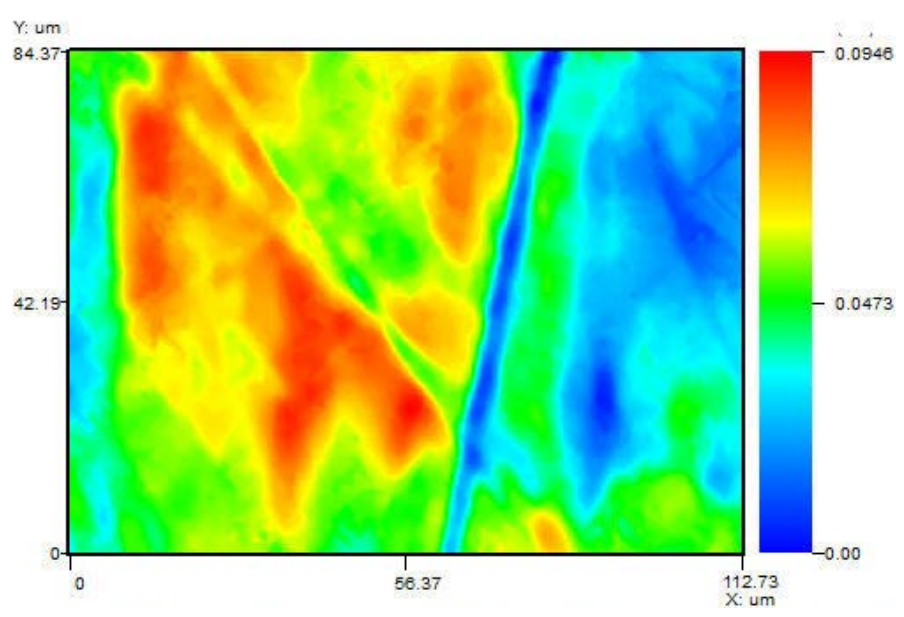

(a)

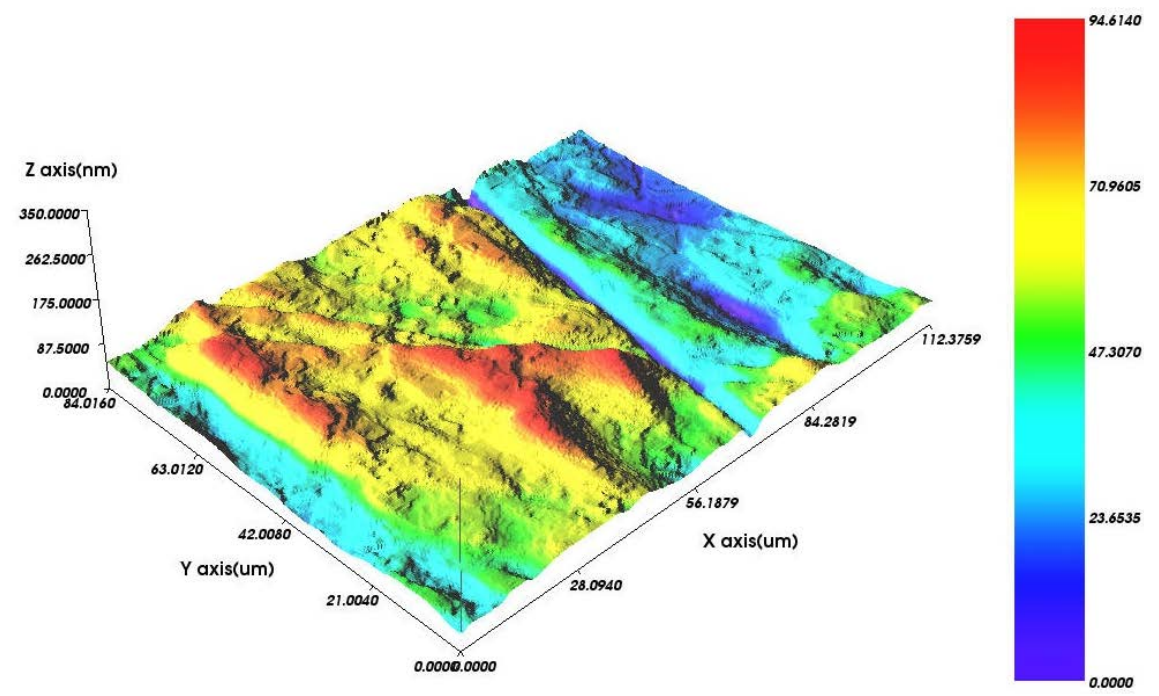

(b)

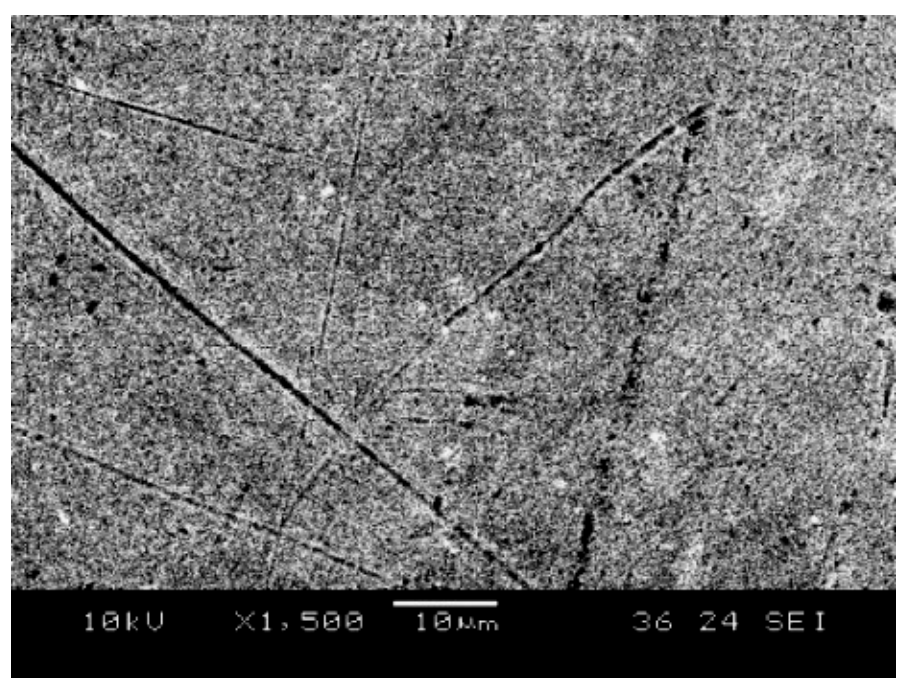

(c)

Figure 4. Measured surface roughness and SEM image with conventional polishing process. (a) Measured surface roughness; (b) 3D profile; (c) SEM image. 


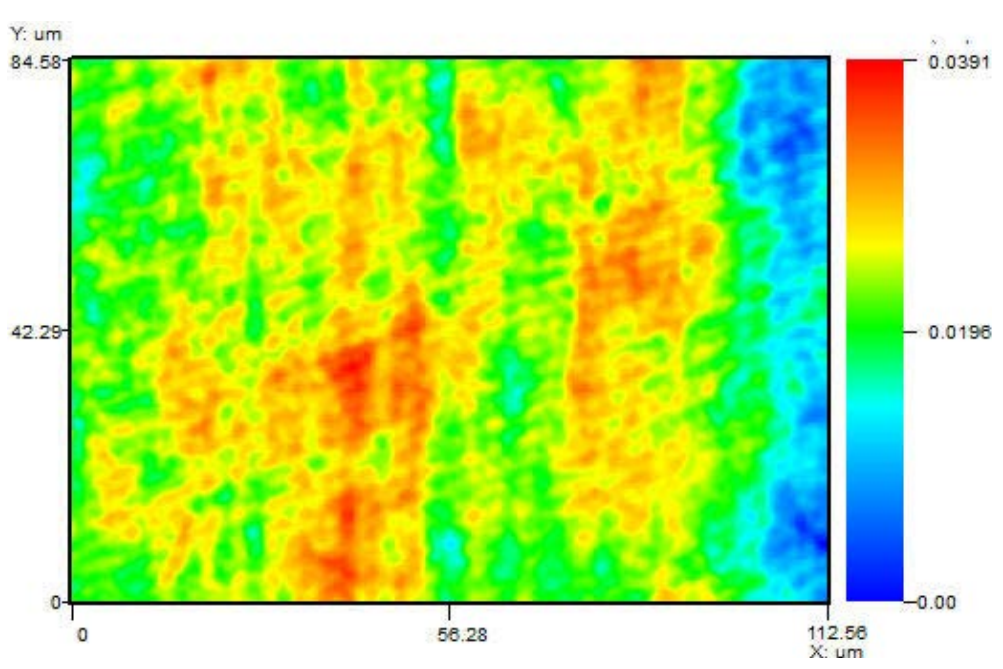

(a)

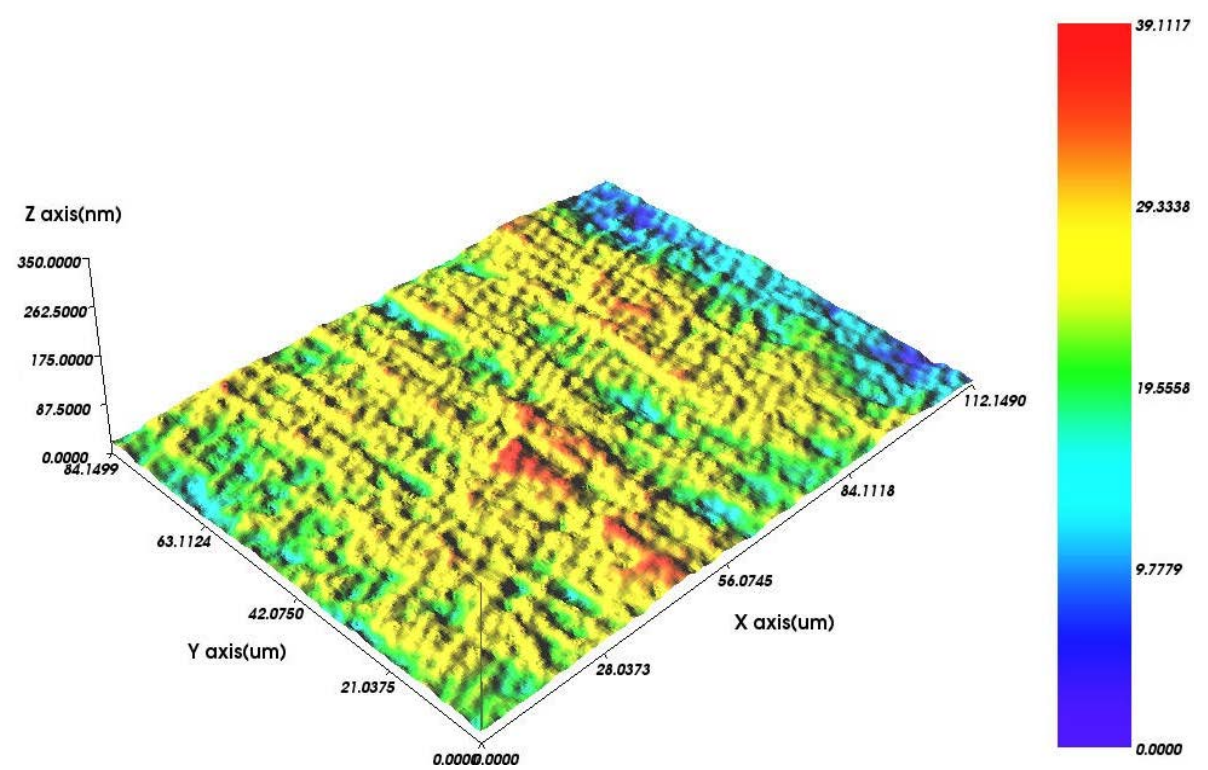

(b)

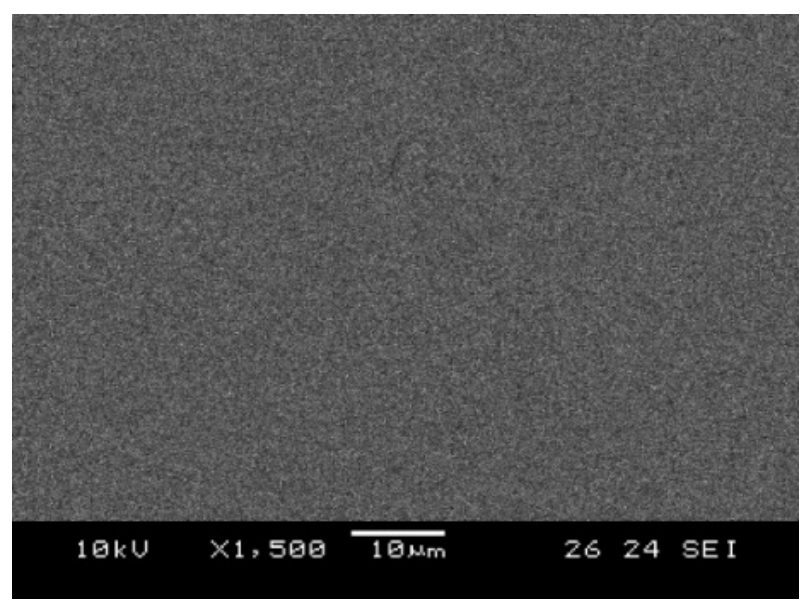

(c)

Figure 5. Measured surface roughness and SEM image with MR polishing process. 
Table 1. Experimental conditions for MR polishing.

\begin{tabular}{ccccc}
\hline Wheel speed & Gap distance & Magnetic intensity & Abrassive slurry & Feed rate \\
\hline $400 \mathrm{rpm}$ & $1 \mathrm{~mm}$ & $1200 \mathrm{G}$ & $\mathrm{Al}_{2} \mathrm{O}_{3}$ & $1 \mathrm{~mm} / \mathrm{min}$ \\
\hline
\end{tabular}

Table 2. Compositions of MR fluid.

\begin{tabular}{cccc}
\hline CI particle & DI water & $\mathbf{N a}_{2} \mathbf{C O}_{3}$ & Glycerin \\
\hline $50 \mathrm{wt} \%$ & $48 \mathrm{wt} \%$ & $1 \mathrm{wt} \%$ & $1 \mathrm{wt} \%$ \\
\hline
\end{tabular}

\subsection{Analysis of Residual Stress}

In this study, HR-XRD (Expert pro, USA) was used to analysis the residual stress. As shown in Figure 6, it shows the results of residual stress after conventional polishing and MR polishing. It can be obtained -38 MPa by conventional polishing and $-34 \mathrm{MPa}$ by MR polishing. The compressive residual stress was still appeared after MR polishing process, but lower than that of conventional polishing. It means that both processes can eliminate the work-hardening layer and generated deformed layer. The stress corrosion crack is generated in tensile residual stress. However, the compressive residual stress is existed in surface both processes. As a result, the problem according to residual stress cannot be occurred.

\subsection{Analysis of Work Hardening}

Work hardening has advantage as increasing mechanical hardness and strength, but decreasing corrosion resistance and elongation. This can be seen in contact mechanical polishing process such as conventional polishing, and can be generated due to deformed layer by the mechanical stress in polishing process.

Nanoindentation is used to measure the hardness for analysis of work hardening property. Using CMS module of Nano Indentor G200 (Agilent Technologies, USA), the hardness and Young's modulus according to pressing depth are measured each polished work pieces. Pressing depth is by $2000 \mathrm{~nm}$.

As Figure 7, the deviation is gradually decreased and consistent between $200 \mathrm{~nm}$ and $500 \mathrm{~nm}$ in conventional polished work piece. While, the deviation can be seen consistent from the beginning press and decreased with increasing the depth after MR polishing process. The reason of large deviation after conventional polishing process is non-consistent surface roughness, increase of dislocation density by mechanical stress and generated work hardening in deformed layer.

Figure 8 shows the Young's modulus after each process. The Young's modulus of conventional polished work piece is not consistent rather than that of MR polished, and the deviation is not decreased with increasing pressing depth. Figure 9 and Figure 10 show the load-distance curve of material surface of each process. The curve is obtained smooth and continuous after MR polishing, but the free from curve is seen after conventional polishing. This phenomenon, which is sharply changed in any load, is called Pop-in. Because of increasing dislocation and crack of material surface in critical load and the dislocation activities of pressed material result in Pop-in. In contrast the Pop-in is not seen in MR polishing process.

The reason of increasing hardness and Young's modulus as Table $\mathbf{3}$ is the deformed property according to the characteristic of shape memory alloy of nitinol. In polishing process, the Phase transform is generated and increased the hardness. The martensite, the component of nitinol, is transformed to detwinned martensite, which of hardness is higher than that of martensite. After MR polishing process, the measured hardness is nearly same as that of raw workpiece, which means that the mechanical stress and material removal rate to workpiece is small. As a result of this, the work hardening is seldom generated. The material removal rate of MR polishing according to nitinol is $550 \mathrm{~nm} / \mathrm{min}$ and the deformed layer generated by conventional polishing is removed. Also, by measuring through nanoindentation, it can be seen that the work hardening is not generated in material for MR polishing.

\subsection{Analysis of Corrosion Test}

Tafel extrapolation can determine corrosion characteristics by X, Y-value due to crossed incline of cathode and anode polarization curve [5]. The crossed point of polarization curve is presented. The crossed point is a corrosion potential $\left(\mathrm{E}_{\mathrm{corr}}\right)$, and polarization is carried out the mainly on the crossed point. 


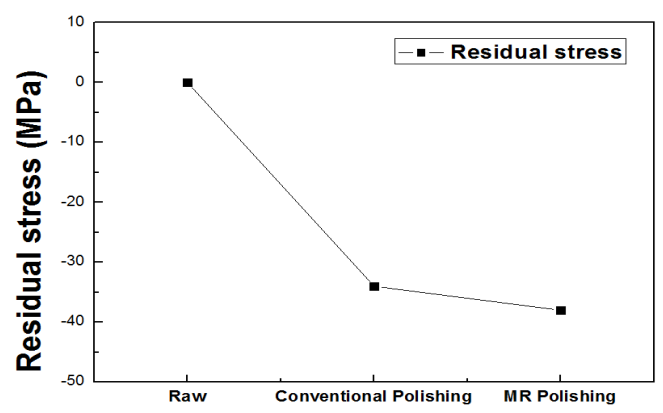

Figure 6. Measured residual stress of raw, conventional polished and MR polished workpiece.

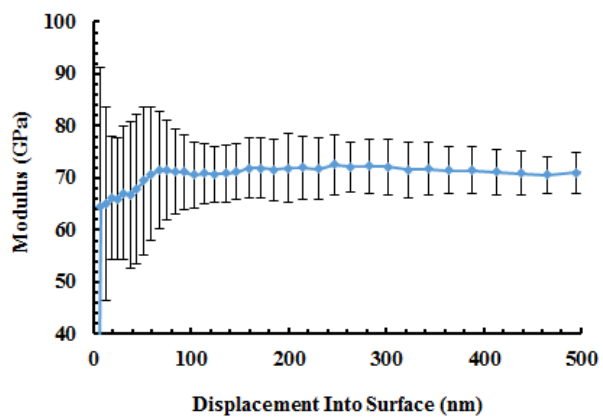

(a)

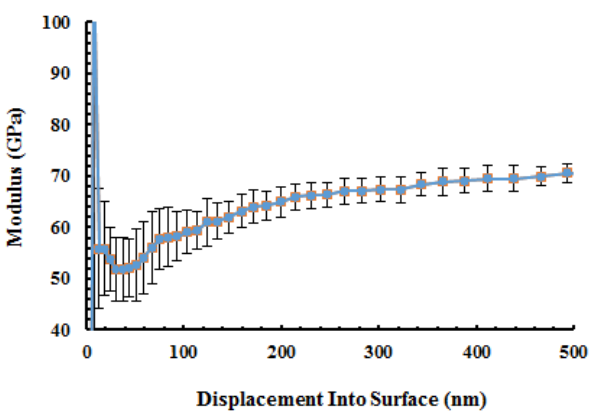

(b)

Figure 7. Measured hardness after conventional polishing and MR polishing. (a) Conventional polishing; (b) MR polishing.

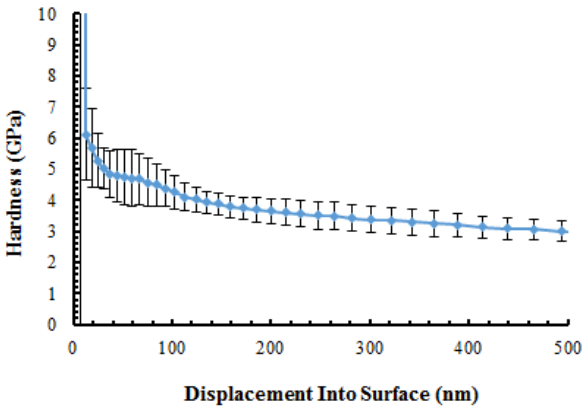

(a)

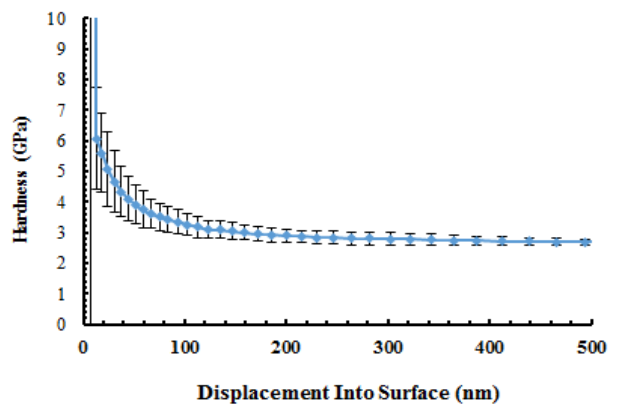

(b)

Figure 8. Measured Young's modulus after conventional polishing and MR polishing. (a) Conventional polishing; (b) MR polishing.

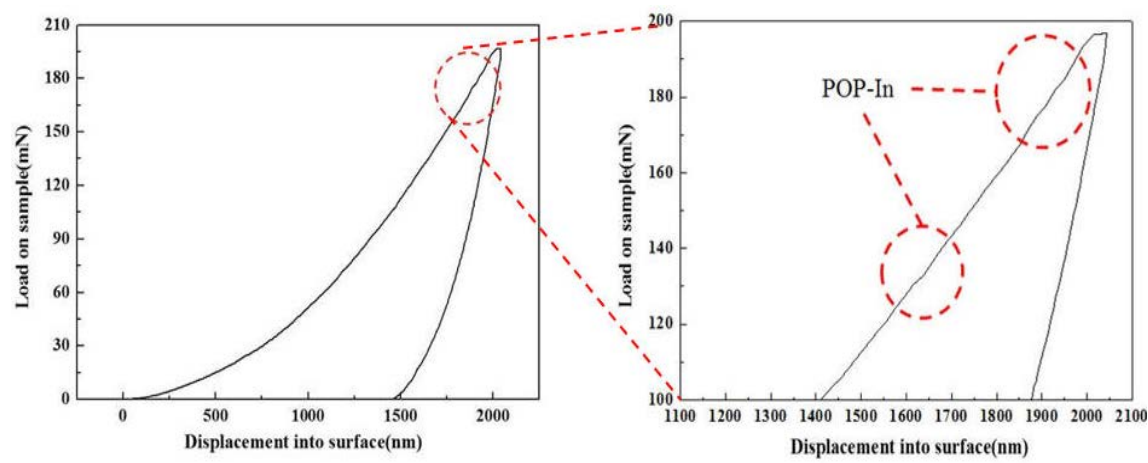

Figure 9. Load-displacement curve after conventional polishing. 


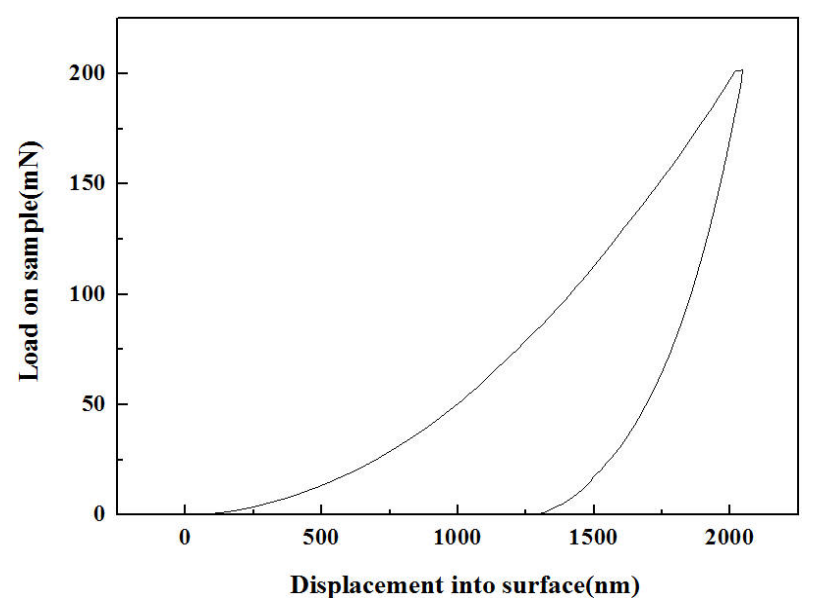

Figure 10. Load-displacement curve after MR polishing.

Table 3. Result of nanoindentation test.

\begin{tabular}{ccc}
\hline & Hardness & Moulus \\
\hline Conventional polishing & $3.91 \mathrm{GPa} \pm 0.37 \mathrm{GPa}$ & $71.2 \mathrm{GPa} \pm 5.4 \mathrm{GPa}$ \\
MR polishing & $3.06 \mathrm{GPa} \pm 0.27 \mathrm{GPa}$ & $61.9 \mathrm{GPa} \pm 3.4 \mathrm{GPa}$ \\
\hline
\end{tabular}

In this study, Potentiostat (EG\&G, PAR 273A, USA) with three-electrode was used to preform corrosion test as Figure 11. Nitinol was used as work electrode, and counter and reference electrode were adopted platinum and $\mathrm{Ag} / \mathrm{AgCl}$. NaCl (9 wt\%) was selected as electrolyte [6]. Nitrogen gas was input to remove the dissolved oxygen, and a series of experiment was performed to create a similar atmosphere of human body.

The results of corrosion test were shown in Figure 12. After conventional polishing, corrosion potential ( $\left.\mathrm{E}_{\text {corr }}\right)$ was $-301 \mathrm{mV}$, but that of MR polishing was $-280 \mathrm{mV}$. It seems to be increased the corrosion potential due to improving the surface roughness. After MR polishing, corrosion current $\left(\mathrm{I}_{\text {corr }}\right)$ was lower than that of conventional polishing. Current was kept constantly with the increasing voltage, which is called Passivation region. This is also seen at low current density. It can be seen that the corrosion resistance is more improved by MR polishing process than conventional polishing process. The improved corrosion resistance can be obtained from the stability of corrosion due to very fine surface roughness [7].

\section{Conclusions}

In this study, conventional polishing and MR polishing process were carried out to investigate the improvement of surface integrity and the surface flaws. Surface roughness, residual stress, work hardening and corrosion properties were investigated. Conclusions of this study are as follows.

1) Surface roughness $(\mathrm{Ra}=12.91 \mathrm{~nm})$ was obtained by conventional polishing process. However, scratches and tool marks still existed. That is, conventional polishing process cannot be used to get a fine surface integrity. In case of MR polishing process, very fine surface roughness $(\mathrm{Ra}=3.72 \mathrm{~nm})$ could be obtained, and scratches and tool mark did not exist.

2) After conventional polishing process, compressive residual stress (38 MPa) was appeared. Existed grinding and polishing process can form compressive residual stress. Therefore, stress corrosion crack from tensile residual stress will appear on the surface. However, MR polishing process was carried out to remove surface flaws. As a result, compressive residual stress (34 MPa) existed. It means that residual stress was eliminated by MR polishing process.

3) The measured hardness after MR polishing using nanoindentation is lower than that of conventional polishing, and the deviation is also consistent. In conventional polishing process, the irregular surface roughness affects the large deviation at early press, and because of work hardening, the hardness according to increasing dislocation densities is increased. The deviation of measurement of MR polishing is decreased. It means that the work hardening is rarely generated in MR polishing and the deformed layer is eliminated using MR polishing process. 


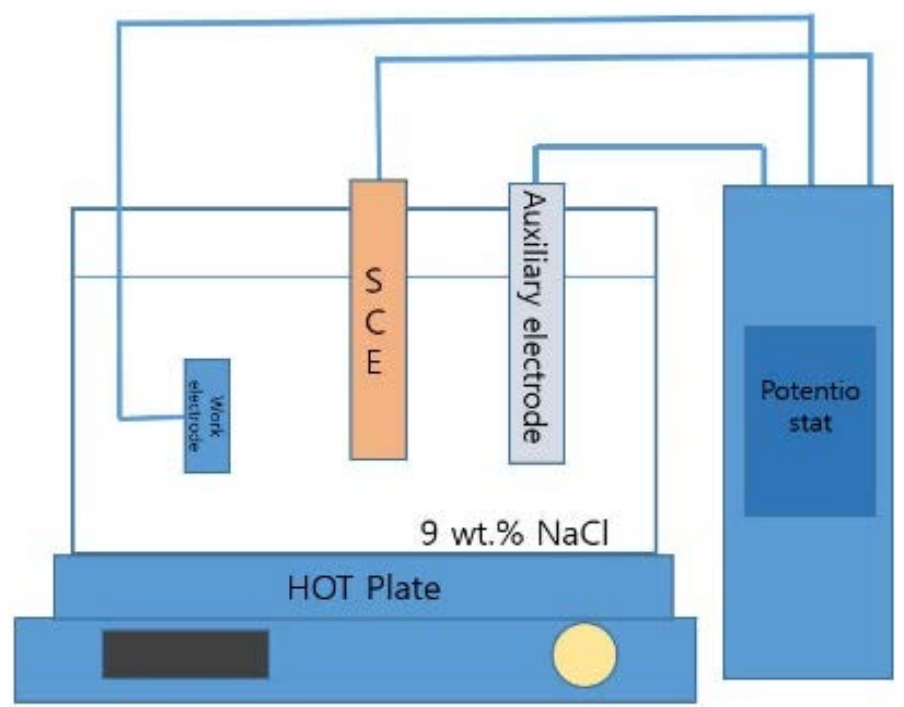

Figure 11. Schematic diagram of corrosion test.

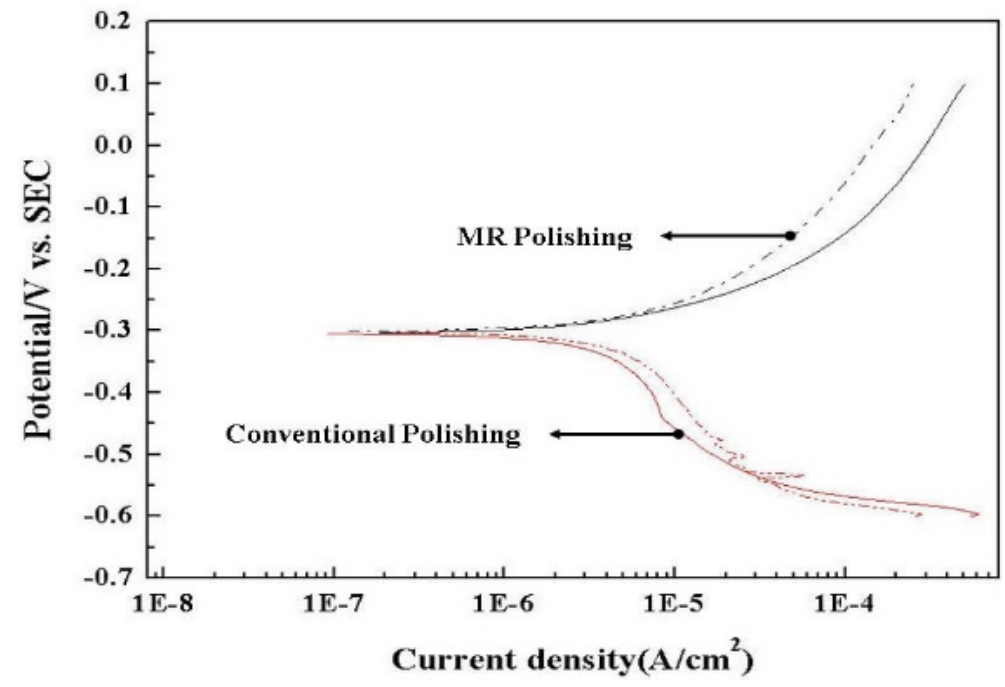

Figure 12. Result of corrosion test with polishing processes.

4) Corrosion potential was $-301 \mathrm{mV}$ after conventional polishing, and in case of MR polishing, it was -280 $\mathrm{mV}$. From this result, it was identified that corrosion resistance was improved. Passivation region whose current has been kept constantly with the increasing voltage was also generated at low current density after MR polishing. It can be seen that MR polishing process is better polishing process than conventional polishing process.

\section{Acknowledgements}

This work was supported by Inha University Research Grant and also partially supported by National Research Foundation of Korea grants funded by the Korean government (NRF-2011-0022129).

\section{References}

[1] Wu, M.H. (2001) Fabrication of Nitinol Materials and Components. Proc. of the Int. Conf. Shape Memo. and Sup. Elas. Tech, 517-521.

[2] Shabalovskava, S. (2002) Corrosion and Biocompatibility Aspects of Nitinol as an Implant Material. Bio-Me. Mater. 
Eng., 12, 69-109.

[3] Wang, J., Li, N., Rao, G. and Han, E. (2007) Stress Corrosion Cracking of NiTi in Artificial Saliva. Dent. Mater., 23, 133-137. http://dx.doi.org/10.1016/j.dental.2006.01.001

[4] Deville, S. (2006) Influence of Surface Finish and Residual Stresses on the Ageing Sensitive of Biomedical Grade Zirconia. Bio. Mater., 21, 2186-2192.

[5] Lee, D.J. and Choi, H.S. Introduction to Electrochemistry. Ajin Publisher.

[6] Liu, C. (2010) In Vitro Electrochemical Corrosion Behavior of Functionally Graded Diamond-Like Carbon Coatings on Biomedical Nitinol Alloy. Thin Solid Films, 496, 457-462. http://dx.doi.org/10.1016/j.tsf.2005.09.109

[7] Nor Asma, R.B.A. (2011) Study on the Effect of Surface Finish on Corrosion of Carbon Steel in $\mathrm{CO}_{2}$ Environment. $J$. of App. Sci., 11, 2053-2057. http://dx.doi.org/10.3923/jas.2011.2053.2057 